\title{
Experiences with the Use of Vaginal Dilator by Cervical Cancer Women Who Received Pelvic Radiotherapy at Cancer Diseases Hospital, Lusaka Zambia
}

\author{
Alex Mwale ${ }^{1 *}$, Patricia Katowa-Mukwato², Victoria Mwiinga Kalusopa ${ }^{2}$, \\ Phadaless Phiri-Sinkamba ${ }^{2}$, Susan Mutemwa² \\ ${ }^{1}$ Cancer Diseases Hospital, Lusaka, Zambia \\ ${ }^{2}$ School of Nursing Sciences, University of Zambia, Lusaka, Zambia \\ Email: mwalex2007@yahoo.co.uk,patriciakatowamukwato@gmail.com,victoriakalusopa@gmail.com, \\ phada.phiri@gmail.com,s_mutemwa@yahoo.com
}

How to cite this paper: Mwale, A., Katowa-Mukwato, P., Kalusopa, V.M., Phiri-Sinkamba, P. and Mutemwa, S. (2021) Experiences with the Use of Vaginal Dilator by Cervical Cancer Women Who Received Pelvic Radiotherapy at Cancer Diseases Hospital, Lusaka Zambia. Open Journal of $\mathrm{Ob}$ stetrics and Gynecology, 11, 1386-1396. https://doi.org/10.4236/ojog.2021.1110129

Received: August 19, 2021

Accepted: October 24, 2021

Published: October 27, 2021

Copyright $\odot 2021$ by author(s) and Scientific Research Publishing Inc. This work is licensed under the Creative Commons Attribution International License (CC BY 4.0).

http://creativecommons.org/licenses/by/4.0/ (c) (i) Open Access

\begin{abstract}
Background: Cancer of the cervix is the commonest cancer in women seen at Cancer Diseases Hospital in Zambia and Pelvic Radiotherapy is the main treatment modality used on cervical cancer patients. Radiotherapy to the pelvis has a potential to causes vaginal stenosis but the stenosis can be prevented by regular sexual intercourse or use of vaginal dilators as recommended by cancer organizations. Despite the well-established benefits of vaginal dilators, there was reluctance by women to adopt this practice as seen by the number of survivors with vaginal stenosis at Cancer Diseases Hospital. The objective of this study was to explore experiences with the use of vaginal dilators by cervical cancer women who received Pelvic Radiotherapy. Methodology: A descriptive phenomenological design was used to explore experiences with the use of vaginal dilators by cervical cancer women. The study was conducted at Cancer Diseases Hospital in Lusaka District of Zambia. Participants were identified and purposefully sampled during the follow up clinics, they were then followed for interviews into their homes in Lusaka and data saturation was attained after interviewing 22 participants. Data were analyzed using thematic analysis. Results: Five themes from the study emerged on how women with cervical cancer experienced the use of vaginal dilator; such as uncomfortable dilators, pity for the husband, changed lifestyle, embarrassment and fear. Conclusion: It was acknowledged that the use of vaginal dilator was associated with negative experiences such as uncomfortable dilators, pity for the husband, changed lifestyle, fear and embarrassment. There-
\end{abstract}


fore, this study recommends that Health care providers from $\mathrm{CDH}$ and other health institutions should give appropriate information to patients concerning the use of vaginal dilators and the Ministry of Health to provide vaginal dilators instead of 50 milliliter syringes currently in use.

\section{Keywords}

Cervical Cancer, Radiotherapy, Experiences, Vaginal Dilators, Vaginal Stenosis

\section{Introduction}

Cervical cancer (CACX) is the fourth most common cancer in women worldwide, [1]. In Zambia, cervical cancer is the most frequent observed cancer among women at Cancer Diseases Hospital (CDH) [2]. Pelvic Radiotherapy (PRT) is the main treatment of CACX given at $\mathrm{CDH}$. After receiving PRT, vaginal stenosis is anticipated in all women and can be prevented by having regular sexual intercourse or use of vaginal dilators [3]. Rehabilitative use of vaginal dilators is a widely endorsed practice by healthcare providers and is regularly prescribed to women who receive PRT as recommended by cancer organizations such as, the American Cancer Society (ACS) and the National Forum of Gynecological Oncology Nurses (NFGON) [4] [5]. The rationale for preventing vaginal stenosis is to support women who wish to have penetrative vaginal intercourse and for clinical examination so that early detection of a potentially treatable CACX recurrence can be made possible [6]. A study on use of vaginal dilators was conducted in Australia to explore patient experiences of dilator use and identify barriers affecting compliance. The major barriers that emerged were uncertainty about dilator use, viewing dilator as a negative experience, lack of time, forgetting and associating it to sex aids [3]. Another study conducted in London, shows that women named barriers such as lack of privacy, time, pain and discomfort while using the dilator [7]. Further, in the article "care for women after radiotherapy" asserted that many women struggled with different thoughts, uncomfortable, embarrassing and fear about vagina dilators [8]. Vaginal stenosis compromises vaginal elasticity and decreases lubrication which results in development of telangiectasia thus increasing the vagina's susceptibility to trauma and infection. Vaginal stenosis can also result in long-term sexual dysfunction and painful vaginal examinations which affect the quality of life in women with CACX, however, it can be prevented by regular sexual intercourse or use of vaginal dilators [9]. Patients in Zambia have been using vagina dilators since 2006 when CDH started its operations. At the time of this study, $\mathrm{CDH}$ was prescribing 50 milliliter syringes as a dilator together with lubricants and condoms. Although vaginal dilators were prescribed, compliance with use has never been evaluated at $\mathrm{CDH}$. Therefore, the objective of this study was to explore the experiences with the use of vaginal dilators by women with CACX who received Pelvic Radiotherapy [10] [11] [12]. 


\section{Methods}

A qualitative descriptive phenomenological design which allowed participants describe their "lived experiences" of using dilators was utilized. The study was conducted in Lusaka District of Zambia. The study population was CACX women who were prescribed with vaginal dilators after receiving PRT and have been attending the CDH Gynecology follow up clinic from April 2006 to three months before commencement of data collection. Participants were identified and purposefully sampled during the $\mathrm{CDH}$ Gynecology follow up clinic, then they were followed for interviews to their homes in Lusaka District. Participants were selected based on the variables such as age, residential area, level of education, marital status and frequency of using the dilator weekly. Data was collected using in-depth unstructured interview schedule with open ended questions which is a recommendation in phenomenological studies, [13]. Face to-face interviews were conducted to allow the researcher collect verbal and nonverbal cues such as gestures and facial expressions, in addition to asking clarifying questions such as "tell us more about the experiences of using the vaginal dilator. Data saturation determined the sample size and it was attained after interviewing twenty-two participants. Ethical clearance was obtained from the University of Zambia Biomedical Research Ethics Committee (UNZABREC), approval number (REF.01809-18). Permission was obtained from the CDH Management and the National Health Research Authority. Consent was obtained from participants following explanations on the purpose, procedure, benefits and risks of the study. Thematic analysis was utilized to analyze data as recommended for qualitative studies.

\section{Results}

Table 1 shows 22 participates interviewed were aged 30 to 69 years and most of them were single while three had no any form of formal education. All participants were living within Lusaka District of which thirteen were from high density area, five from medium density area and four from low density area. Eleven were using the dilator twice weekly, six were using it three times weekly, two were using it once a week.

Five themes emerged from the data as shown in Table 2.

Table 2 shows five major themes that emerged regarding how participants

Table 1. Socio-demographic and clinical characteristics.

\begin{tabular}{ccccc}
\hline Variable & \multicolumn{4}{c}{ Description and number of participants } \\
\hline Age range & \multicolumn{2}{c}{30 to 69 years (22) } & Tertiary (3) \\
Level of Education & No formal education (3) & Primary (9) & Secondary (7) & Single (12) \\
Marital status & Married (10) & & Medium density (5) \\
Residential area & High density (13) & Twice weekly (11) & Three times a week (6) & Three times daily (3) \\
Use of dilator & Once weekly (2) & The &
\end{tabular}


Table 2. Themes and sub themes.

\begin{tabular}{ccc}
\hline Themes & Sub themes & Identity number \\
\hline Uncomfortable & Big Painful hard syringe, vagina injury & $1,3,8,13,15,16$ \\
Fear & Burden of Carrying and storing condoms & $2,3,7,17,21$ \\
Changed lifestyle & Treatment but lacking privacy and time & $2,3,6,7,10,11,15,18,21,22$ \\
Pity for Husband & Jealousy and supportive husband & $1,9,12,17,19$ \\
Embarrassment & Unpleasant and sinful act & $4,10,12,14,16$ \\
\hline
\end{tabular}

experienced the use of vaginal dilators. They described the use of vaginal dilators as uncomfortable, cause of fear, changed lifestyle, pity for the husband and embarrassing. Most participants experienced at least three of the prominent themes as discussed below.

\section{Theme 1: Uncomfortable Dilator}

The first theme was uncomfortable dilator, six out of twenty-two women experienced the use of vaginal dilators as uncomfortable because of the dilator design (syringe) which was hard, painful and caused injury to the vagina. Most women desired a more pleasurable dilator made out of softer material. Few participants never used the dilator adequately, because it was too painful and caused injury to the vagina. One participant complained "just seeing a big syringe puts her off and was gripped with fear. Two other participants who experienced uncomfortable use of dilators said "The syringe is hard and it caused injuries to the vagina, the hospital should give items made of softer material" participant 5 and 8. Another participant indicated that "Although it is treatment, the syringe design is hard and painful. Kindly redesign the syringes so that it looks like a penis prosthesis which is soft, don't give us hard syringes", Participant 1. "The syringe is too hard and big. I sometimes bleed after using the dilator. It is bad I don' like that syringe at all. If it was not medical advice, I was going to stop using it Participants 15". The process is not pleasant, I do not see any reason why I should dilate. A syringe reminds me of cancer and its treatment especially the painful brachytherapy. Why are you troubling me with this hard-painful syringe" Participant 22. Two participants indicated that it was not normal to use the dilator, "I had to pray to God to give me strength and clear my conscious. That man (syringe) is ever hard kindly employ young men to be dilating us or redesign the syringes to look like a penis which is soft, Participant 13 and 16 ".

\section{Theme 2: Fear}

The theme on fear shows that five out of twenty-two women experienced fear of carrying and keeping a lot of condoms at home. The actual procedure of dilator utilization was burdening to the participants. Almost all participants had fear of being found in possession of condoms. They also had a fear of actual use of dilator because family and community members may accuse them of liking too much sexual despite having CACX. The process of carrying condoms from $\mathrm{CDH}$, storage and disposal at home caused fear to participants because condoms in Zambian communities are associated with sex workers and it is a perceptive ab- 
normality for a woman to be found in possession of condoms as indicated by some participants:

"Imagine as old as am, carrying condoms, I make sure that I hide the condoms when am travelling from $C D H$ and when am at home" participant 7. "The process was part of treatment but the burden of keeping condoms is troubling me, in case anyone discovers the condoms, they may accuse me of promiscuity, I told all my children that condoms were part of treatment. I even warned my sons not to steal the condoms" participant 3. "The process is not easy especially carrying the condoms from the hospital and keeping a lot of condoms at home. I told my two sisters to destroy the boxes of condoms in case I die or when I am very ill. What will people say when they discover the condoms in my room Participant 17" Two out of twenty-two women experienced the actual use of dilator as a burden because it needed privacy and good timing to use it. Participants had limited time and privacy for dilator use as indicated. "The process of vaginal dilator use is affecting me socially like going to visit my relatives and friends. 'Am even failing to visit friends and family because of the same dilator, I may not have time and privacy to use the dilator when I go visiting" Participant 2. "The first two weeks I used to feel bad when using the dilator but I had to force myself to continue using the dilator because it was treatment. When condoms are finished, I have fear of going to buy but my husband goes to buy because it looks very awkward for a woman to go and buy condoms from the chemist' Participant 21.

\section{Theme 3: Changed life style}

On the theme, changed Life Style; participants had similar challenges regarding their life styles while using the dilator. At the time of interview, five out of 22 participants experienced the use of vaginal dilator as part of treatment. Although it was part of treatment all participants had limited social interactions such that they could not visit friends, relatives or go to camp meetings and funerals for more than three days mainly due to the dilator. The changes in life style due to use of vaginal dilator is evident in participants' statements below: "If it was not a medical advice, I was going to stop using the dilator. Cancer treatment is a long term activity which is not ending, just imagine chemoradiotherapy for 6 weeks and use of vaginal dilator for 2 years", Participants 7, 15, 18, 21 and 22. Three participants complained about difficulties to find time and privacy to use dilators. "The use of vaginal dilator is affecting me socially like failing to visit my relatives and friends because I may not have time and privacy to use the dilator when I go visiting" Participant 2. "The process is tough in the sense that I have to use the dilator 3 times daily. I have to leave my work place (market) at lunch time when my children are at school to go and dilate at home, it s like taking medication. I know all those who come to $\mathrm{CDH}$ use the syringes and it motivates me a lot" participant 3. "Sometimes I ask myself the reasons why am using the dilator as old as am. It has been a very difficult process because of lack of priva$c y$, I share the bedroom with my 2 granddaughters, $i$ have to use the dilators 
when they are at school, participant 11. One of the participants was told to stop using the dilator because it was above the prescribed period of 3 years, but the participant said "I will continue using the dilator because if I don't use it for 3 continuous days, the vagina closes up and there is feeling of abdominal fullness. I swear to continue using the dilator for life". Another participant mentioned that she did know why the vagina should be kept patent since the husband was dead "I don't know the reasons why am using the dilator since my husband is dead" Participant 10.

\section{Theme 4: Pity for the Husband}

Another theme was pity for the husband, five participants expressed concerns about their husbands who were either jealousy or supportive. Jealousy husbands did not welcome the use of vaginal dilators because it denied them sexual intercourse. Supportive husbands were of great encouragement to participants by welcoming the use of dilator and not allowing their wives to go and look for condoms from the pharmacy or health centres when they faced a shortage of condoms at home. "It is very embarrassing especially if your husband is watching, the process initially caused a misunderstanding with my husband but after explaining to him, he is the one who has been dilating using the syringe. It seems he has also lost sexual feelings for me. I explained to him that we can be having intercourse but he has never shown any interest. I am requesting the hospital to be involving our husbands during the counselling" Participant 12. "During the use of a dilator my husband was ever upset. I only used the dilators for 5 months, my husband threw them away because he enjoys the vaginal tightness and does not want to use condoms because he does not know the reasons why condoms should be used" Participant 9. "The Dilator brought problems at home although it protected me from having sex with my husband because I used to insert the dilator the whole night and sleep with it until morning so that he does not demand for sex" Participant 17. Some husbands were very supportive and not comfortable to let their wives go and buy condoms when they were finished. "When condoms are finished my husband does not allow me to go and buy because it looks very awkward for a woman to go and buy condoms from the chemist" Participant 19'. "The process of using the dilator makes me miss my late husband he would have been supporting and helping through sexual intercourse" Participant 1.

\section{Theme 5: Embarrassment}

Embarrassment was another prominent theme where participants indicated that the actual use of vaginal dilator and the issue of looking for condoms was embarrassing. They were even shy to talk about the use of dilators to friends and family members and one participant was viewing the use of dilator as a sinful act. "It is a very bad and embarrassing process for old people like me but I am doing it because it is the advice from the hospital" it is also embarrassing to go and ask for condoms from the local health center, when looking for condoms, what will other people think about me' Participant 10. "It is very embarrassing 
and awful process especially if your husband is watching, the process initially caused a misunderstanding with my husband" Participant 12. "The process was embarrassing and terrible when inserting the dilator, it always reminded me of the cancer and bleeding I used to have," Participant 14. "It is not normal to use a dilator, it's a sin, I had to pray for forgive and strength to clear up my conscious but I would rather die with a vaginal stenosis than going to hell'. Participant 16.

\section{Discussion}

The study was prompted by the few cases of vaginal stenosis seen from patients who were followed up after receiving PRT at $\mathrm{CDH}$. The experiences of using vaginal dilators is based on 22 participants who described their lived experiences of using a dilator. Five major themes emerged regarding how participants experienced the use of vaginal dilators such as uncomfortable dilators, fear, changed lifestyle, pity for the husband and embarrassment. Use of vaginal dilators caused discomfort as they are unnatural devices and therefore participants from this study complained about the uncomfortable dilators which were hard, painful and caused injuries to the vagina. Few participants never used the prescribed syringe because it was too painful, they desired a more pleasurable dilator made out of softer material. Other participants complained about how "upon seeing a big syringe puts them off and they were gripped with fear" because the sight of a syringe reminded them of the process of using the dilator and the painful experience they underwent. The findings on uncomfortable dilators are similar to the findings by Bakker, et al., [14] who reported that women had emotions regarding dilator use or its hard-plastic design which caused pain, blood loss, and associating it to brachytherapy insertion [15]. Some women mentioned a lack of instrumental support, such as lubricants.

In this study participants also were experiencing the fear of carrying and keeping a lot of condoms at home, because of the nature of the syringes which are used as dilators, women were given condoms to dress the syringes and make them a bit comfortable. The issue of condoms disturbed participants psychologically because they always had thoughts of being accused of liking too much sex despite having CACX. Most participants complained that carrying condoms from $\mathrm{CDH}$ to their respective homes was burdensome such that, 'the bags carrying condoms were highly guarded so that no one should see what they were carrying. On the storage and disposal of condoms, participants faced the fear of keeping and disposing a lot of condoms at home since condoms are always associated with sex workers and the actual use of dilator was a burden because it needed privacy and good timing to use it. Most studies consulted shows that there was no literature to support the finding on the complaint about condoms but one study by Bakker and Vermeer [5], reports that some women complained about lack of instrumental support such as lubricants during the use of vaginal dilators.

This study also revealed that, the use of vaginal dilator changed the lifestyle of 
several participants as a restriction to some activities and as an extension of long-term cancer treatment which never ends. The restricted social life by some participants were failing to visit relatives, friends and church camp meetings or funerals for more than three days. Those participants who were in employment had to abandon work during working hours to go and use dilators at home. Furthermore, participants complained about lack of privacy at home because they were staying with other family members with whom they were sharing the bedroom. Others had concerns about dilator use because they lacked understanding as to why they were using the dilators as indicated by one participant who did not have convincing reasons why she was using a dilator. In this study, lack of understanding on the use of dilators can be attributed to insufficient health education given to patients after finishing radiotherapy. This result on lack of time and privacy is supported by Bakker, et al., [14] whose study shows that women also experienced lack of time, privacy, forgetting, or feeling tired when using the dilator. Similar experiences to this study on extension of cancer treatment and prolonged treatment were also reported by Milross, et al., [3] who reported that facilitators to use of dilators included acceptance of dilator use as part of their normal routine or an extension of medical treatment and focusing on positive aspects. Another experience expressed by participants was pity for their husbands ranging from jealousy to supportive husbands. Jealousy husbands did not welcome the use of vaginal dilators because the dilator denied them sexual intercourse but supportive husbands were of great encouragement to participants by welcoming the use of dilator and not allowing their women to go and buy condoms from the pharmacy when they were finished at home. Some single participants missed their partners and wished they had someone to have regular sexual intercourse with instead of using the dilator. Literature reviewed could not support or deny the findings on pity for the husband. Furthermore, other themes that emerged from participant's experiences were embarrassing and unpleasant procedure. Participants indicated that the use of vaginal dilator and the issue of looking for condoms was embarrassing. They were shy to talk about the use of dilators to friends and family members. Most participants indicated that the procedure was unpleasant in the sense that they felt that dirty from the condoms and lubricants was retained inside the vagina and associating the procedure to masturbation and it was a sin to use the dilator. Participants with very strong religious belief indicated that they would rather die with a vaginal stenosis than to continue using a dilator and go to hell. This study finding on embarrassment is similar to that study by Cullen, et al., [7] whose report in Canada shows that majority of women were faced with some degree of embarrassment surrounding dilator use due to the perceived sexual nature of the device.

\section{Conclusion}

The use of vaginal dilators was reported as a negative experience to those using

it. From this study, most participants indicated that use of vaginal dilator was 
long term treatment although almost half of them reacted negatively to their use. Participants had fear of carrying and keeping condoms at home and also, they were disturbed psychologically for they always had thoughts that the use of dilators was a sinful act while others had pity for their husbands. Other themes that emerged from participant's experiences were painful dilators and embarrassing procedure. Participants experienced the use of vaginal dilator as a lifestyle changer since they could not attend to social functions such as funerals, visiting family and friends because they may not have privacy and time to use the dilator. They were even shy to talk about the use of dilators to friends and family members for fear of being accused of sexual deviation and masturbation. The negative experience is an indication that the use of vaginal dilators caused physical, social, spiritual and psychological pain to the women.

\section{Recommendation}

Health care providers must proactively provide health related massages for the patients to acquire more knowledge on the use of vaginal dilator. All Healthcare facilities in Zambia should be educated about the use of vaginal dilators by CACX women who receive PRT so that necessary vaginal dilator accessories can easily be accessed by those who stay far from $\mathrm{CDH}$. The study further recommended that the hospital should provide appropriate comfortable vaginal dilators which cause no pain and discomfort instead of issuing $50 \mathrm{mls}$ syringes.

\section{Limitations of the Study}

One limitation of this study was that it was based on the participants self-reporting and it was difficult to objectively verify the answers given; this was however mitigated by asking probing questions and clearing the misunderstandings. Another limitation was that, there was recall bias, since some participants had used the Dilators several months before the study was conducted.

\section{Declaration}

We declare that this Dissertation represents our own work and that all sources quoted have been cited and acknowledged by means of complete reference. We further declare that this dissertation has not been previously submitted for a degree, diploma or other qualification at University of Zambia or another University.

\section{Acknowledgements}

Special thanks to the Ministry of Health for allowing us to conduct the study at Cancer Diseases Hospital, all participants for providing information and all the cited documents for the literature.

\section{Conflicts of Interest}

The authors declare no conflicts of interest regarding the publication of this paper. 


\section{References}

[1] International Agency for Research on Cancer-Global Cancer Statistics (2018) GLOBOCAN Estimates of Incidence and Mortality Worldwide. http://gco.iarc.fr

[2] Cancer Diseases Hospital (2019) Action Plan.

[3] Milross, C., Philp, S., Bonner, B., Nattress, K., Anderson, C., Carter, J. and Juraskova, I. (2012) Chore or Priority; Barriers and Facilitators Affecting Dilator Use after Pelvic Radiotherapy for Gynecological Cancer. Support Care Cancer, 20, 2305-2313. https://doi.org/10.1007/s00520-011-1337-z

[4] American Cancer Society (2014) Coping with Cancer in Everyday Life. https://www.cancer.org

[5] Bakker, R., Vermeer, W.J., Nout, R.A. and Kulie, M. (2014) Qualitative Accounts of Patient's Determinants of Vaginal Dilator Use after Pelvic Radiotherapy. Journal of Sexual Medicine, 12, 764. https://doi.org/10.1111/jsm.12776

[6] Miles, T. and Johnson, N. (2014) Vaginal Dilator Therapy for Women Receiving Pelvic Radiotherapy. Cochrane Database of Systematic Reviews, No. 9, CD007291. https://doi.org/10.1002/14651858.CD007291.pub3

[7] Cullen, K., Fergus, K., Das-Gupta, T., Fitch, M., Doyle, C. and Adams, L. (2012) From "Sex Toy" to Intrusive Imposition: A Qualitative Examination of Women's Sex Experiences with Vaginal Dilator Use following Gynecological Cancer Treatment. The Journal of Sexual Medicine, 9, 1162-1173. https://doi.org/10.1111/j.1743-6109.2011.02639.x

[8] Jolicoeur and Hamilton (2015) Care for Women after Radiotherapy. Canadian Association of Nurses of Oncology.

[9] Vermeer, W.M., Bakker, R.M., Kenter, G.G., Stiggelbout, A.M. and Kuile, M.M. (2015) Cervical Cancer Survivors' and Partners' Experiences with Sexual Dysfunction and Psychosexual Support. Support Care Cancer, 24, 1679. https://doi.org/10.1007/s00520-015-2925-0

[10] National Forum of Gynecological Oncology Nurses (2012) International Guidelines on Vaginal Dilation after Pelvic Radiotherapy.

[11] Punt, L. (2011) Patient Compliance with the Use of Vaginal Dilators following Pelvic Radiotherapy for Gynaecological Cancer. Journal of Radiotherapy in Practice, 10, 13. https://doi.org/10.1017/S1460396910000476

[12] Sydney Gynaecological Oncology Group (2012) Guidelines for the Use of Vaginal Dilators in Women Receiving Pelvic Radiotherapy and Brachytherapy. https://www.uhn.ca/PatientsFamilies/Health_Information/Health Topics/Docume nts/How to Manage Vaginal Stenosis.pdf

[13] Creswell, J.W. (2013) Qualitative Inquiry and Research Design: Choosing among Five Approaches. 3rd Edition, Sage Publications, Washington DC.

[14] Bakker, R.M. and Vermer, W.M. (2014) Sexual Rehabilitation after Pelvic Radiotherapy and Vaginal Dilator Use: Consensus Using the Delphi Method. International Journal of Gynecological Cancer, 24, 499-506. https://doi.org/10.1097/IGC.0000000000000253

[15] Pessi, M.R., Feuercgutte, K.K., Rosa, L.M., Hammerschmidt, K.S.A., Radünz, V. and Alvarez, A.M. (2016) Prevention of Vaginal Stenosis after Brachytherapy: Nursing Intervention. Journal of Nursing, 10, 3495-3502. 


\section{Appendix: Data Collection Tool, Unstructured Interview} Schedule

\section{SECTION A: DEMOGRAPHIC CHARACTERISTICS}

1) What is your age range in year?

2) What is your marital status?

3) What is your occupation?

4) What is your Level of education?

\section{SECTION B: EXPRIENCES WITH THE USE OF VAGINAL DILATOR}

5) How long have you been using a vaginal dilator?

6) How many times do you use the dilator in a week

7) What has been your experience with the use of a vaginal dilator?

8) Tell us more about the lived experiences with the use of a vaginal dilator 